\title{
The Synergistic Effects of Cavitation Erosion-Corrosion in Ship Propeller Materials
}

\author{
J. Basumatary ${ }^{1} \cdot$ M. Nie ${ }^{1} \cdot$ R. J. K. Wood ${ }^{1}$
}

Received: 15 December 2014/Revised: 3 March 2015/Accepted: 5 March 2015/Published online: 25 March 2015

(c) Springer International Publishing AG 2015

\begin{abstract}
Synergy tests were performed for two most common propeller materials, duplex stainless steel (DSS) and nickel aluminium bronze (NAB), by means of an indirect ultrasonic vibratory system. Tests were conducted for pure cavitation erosion in distilled water, pure corrosion using in situ electrochemistry under $3.5 \% \mathrm{NaCl}$ solution and a combination of cavitation erosion-corrosion to understand the overall synergism existing between the two. The results were analysed using gravimetric as well as volumetric analysis. Alicona and Talysurf were employed for the surface topography, and scanning electron microscope was used to see the microstructural morphologies of the samples under different conditions. As a result, the electrochemical tests held at open circuit potential showed that, although DSS exhibited higher resistance to corrosion under seawater alone, NAB exhibited much higher resistance to corrosion when subjected to cavitation. From the experiments conducted, it was concluded that synergy had measurable impact on the cavitation erosion-corrosion of both NAB and DSS. NAB was found to be more susceptible to erosion under both the conditions as compared to DSS with prominent selective cavitation erosion of alpha phase in the microstructure. The overall synergism of NAB was found to be higher than that of DSS.
\end{abstract}

Keywords Cavitation - Cavitation erosion - Cavitation erosion-corrosion $\cdot$ Propeller materials $\cdot$ Nickel aluminium bronze $\cdot$ Duplex stainless steel

\section{J. Basumatary}

jan.basumatary@gmail.com

1 National Centre of Advanced Tribology in Southampton (nCATS), University of Southampton, Southampton, UK

\section{Introduction}

The simultaneous existence of mechanical erosion and electrochemical corrosion is a common scenario for engineering alloys used in marine environments, such as pump impellers and valves. The situation is further complicated by the fact that the effects of erosion and corrosion are in general not additive owing to the interaction between them. The overall damage arising from erosion and corrosion including the interaction between them is termed cavitation erosion-corrosion. The relative significance of corrosion, erosion and the interaction between them depends on the material and the environment system [1]. The nature of the interaction is determined by a number of factors, the more important ones being the passivity of the metal surface, the adherence of the corrosion product, the metallurgical state of the metal, the significance of the diffusion of dissolved oxygen, the presence of aggressive ions and the intensity of cavitation. These factors would determine the mode of corrosion and the rate of erosion-corrosion loss [2-4].

Several studies have been conducted and proven the existence of synergy between cavitation erosion and corrosion, and that this synergy can have a significant effect on the cavitation behaviour of the test materials [5-12]. Vyas and Hansson [1] conducted the ultrasonic vibrating cavitation on stainless steel (SS) in $3.5 \% \mathrm{NaCl}$ solution, and they found that the degree of intergranular corrosion of the sensitized SS increased with increasing cavitation density. They confirmed that for stainless steels due to the existence of the passive film, cavitation could accelerate or decelerate corrosion, depending on the intensity of cavitation and the metallurgical state of the SS specimens. Tomlinson and Talks [3] studied the cavitation erosion-corrosion of various types of cast iron in $3 \%$ sodium chloride solution and found that the fractional weight loss due to pure corrosion ranged 
from 1 to $10 \%$, while that due to corrosion-induced erosion ranged from 16 to $90 \%$. Between 1998 and 2006, Kwok C.T. performed several experiments on laser-treated metals such as austenitic steel alloy and $\mathrm{NiCrSiB}$ alloy in $3.5 \%$ $\mathrm{NaCl}$ solution. It was found that the synergism was responsible for 50-70\% of total loss for laser-alloyed 1050 steel specimen and $20 \%$ for laser surface-alloyed 316 SS specimen, and the cavitation erosion-corrosion resistance was noticed improved for 1050 and $316 \mathrm{SS}$, respectively [13-18]. In 2000, Kwok, Chen and Man conducted another ultrasonic vibrating cavitation at $20 \mathrm{kHz}$ on nine different kinds of metals including cast irons and SS under $3.5 \%$ $\mathrm{NaCl}$ solution [19]. From the experimental results, it was found that synergism had a significant effect on mass loss with up to $85 \%$ total damage. This synergy effect was found to be due to several factors such as impact of corrosive solution, the material property and also the type of materials itself. The most significant impact was found at a mild corrosive environment [4, 20-22].

Few studies have also been conducted on ship propeller materials such as SS, copper alloys, manganese bronze and nickel aluminium bronze (NAB) among others. A synergy experiment conducted by Kwok, Cheng and Man ranked austenitic (304) stainless steels to have very high cavitation erosion resistance than austenitic 316 SS owing to its higher martensitic transformability and work hardenability and lower stacking fault energy of $25 \mathrm{~mJ} \mathrm{~m}^{-2}$ [23]. They also concluded that materials with high corrosion resistance such as copper alloys also displayed higher resistance to the erosion-corrosion synergy. They established that the effect of cavitation on corrosion behaviour particularly depended on two main effects of cavitation, corrosion film detachment and increase of mass transport [10]. Several cavitation corrosion tests were conducted by Al-Hashem, Caseres, Riad and Shalaby on propeller materials like castnickel aluminium bronze (NAB) and duplex stainless steel (DSS) in seawater using 20-kHZ ultrasonic vibrator under free corrosion and cathodic protection conditions, and they found that for DSS, the rate of mass loss was reduced by $19 \%$ under cathodic protection, slightly reducing the subsequent number of cavities as a result. The attack was seen to be concentrated in the austenite phase but was eventually seen to spread to the ferrite phase. This was associated with ductile tearing, cleavage-like facets, river patterns and crystallographic steps at later stages. Specimen cross-sections revealed microcracks at the bottom of the cavities initiating from the ferrite matrix with crack propagation impeded by the austenite islands, branching along the parallel slip systems. They also observed an active shift in the free corrosion potential by about $140 \mathrm{mV}$ when cavitation was applied, with a slight increase in the cathodic and anodic currents, shifting the corrosion potential in the noble direction by $75 \mathrm{mV}$ [24].
However, their cavitation corrosion test of NAB showed a decrease of rate of mass loss by $47 \%$ under cathodic protection and a shift in corrosion potential in the active direction by $70 \mathrm{mV}$. This could be attributed to the cushioning of bubble collapse by cathodic gas and elimination of electrochemical dissolution. They also observed under the optical and scanning electron microscopy that NAB seemed to suffer from selective corrosion of the copperrich $\alpha$ phase at its boundaries with intermetallic $\kappa$ precipitates, while the $\kappa$ precipitates and precipitate-free areas did not suffer corrosion. Also, it was found that selective corrosion was enhanced by cavitation erosion. Under only cavitation, large cavities were found with $\alpha-\kappa$ grainboundary corrosion around the pit edge, whereas, in the presence of cathodic protection, the number of cavities was found to increase but the grain-boundary attack was seen to be absent. They also found microcracks of $5 \mu$ to $10 \mu \mathrm{m}$ length were observed in the $\alpha$ phase adjacent to $\kappa$ precipitates along the cross section of the material. Selective phase corrosion and cavitation stresses were implicated as the causes of cracking [25, 26].

However, despite all the studies done so far, the study on synergistic effects existing between erosion and corrosion were usually carried out under different conditions by different authors, making results difficult to compare. Synergy can be measured in terms of two most common factors, mass loss incurred by combined contribution of erosion and corrosion or the mean depth of penetration (MDP) rate. The equation for synergy is commonly written as

$T=S+E+C$.

Here, $T$ is the total mass loss or overall cavitation erosion-corrosion rate, $C$ is the pure corrosion contribution; $E$ is the pure erosion contribution, and $S$ is the combined contribution due to synergistic effect. $S$ can be also represented as in Eq. 2:

$S=T-(E+C)=\Delta E+\Delta C$,

where $\Delta E=$ corrosion-enhanced erosion and $\Delta C=$ erosion-enhanced corrosion. The present study was carried out in order to understand the existence of synergism between erosion and corrosion in the overall cavitation erosioncorrosion damage of the two most commonly used ship propeller materials, 2205 DSS and CuAl10Ni cast-NAB in $3.5 \% \mathrm{NaCl}$ solution at room temperature [10].

\section{Experimental Method}

The experiment for synergy between cavitation erosioncorrosion was conducted using indirect ultrasonic cavitation rig. Although several tests have been conducted in the 
past using an ASTM G-32 direct cavitation system where a round sample disc is threaded into the probe tip; however, the contact between the sample material and the probe material could render electrochemical analysis difficult and could cause possible galvanic corrosion between the two resulting in either over- or under-evaluation of the corrosion-induced loss, and hence an indirect ultrasonic vibratory cavitation system was used instead of the direct system. Ultrasonic vibratory transducer UIP1000hd with a sonotrode horn made from titanium of diameter $15.9 \mathrm{~mm}$ was used for the cavitation experiment at a frequency of $20 \mathrm{kHz}$ and a peak-to-peak amplitude of 80 micron at room temperature of $17 \pm 0.5{ }^{\circ} \mathrm{C}$. The test samples were placed under an ultrasonic transducer with a vibrating probe of diameter $15.9 \mathrm{~mm}$ kept at a distance of $2 \mathrm{~mm}$ above the specimen surface for $1 \mathrm{~h}$. The samples were tested for cavitation erosion in $5 \mathrm{~L}$ of distilled water, for cavitation corrosion in $5 \mathrm{~L}$ of $3.5 \% \mathrm{NaCl}$ aqueous solution using in situ electrochemistry kept at open circuit potential (OCP) and finally for cavitation erosion-corrosion in $3.5 \%$ $\mathrm{NaCl}$ solution with in situ electrochemistry kept at OCP.

Precision weighing machine $( \pm 0.01 \mathrm{mg})$ was used to measure the gravimetric mass loss of each sample. Alicona measurements were taken using Alicona 3D optical profilometer to measure the volumetric mass loss of the samples along with surface roughness of cavitated regions and compared with each other, as well as surface topography. Form Talysurf $120 \mathrm{~L}$ was also employed to capture the overall surface roughness. Scanning electron microscopy was used to analyse the different microstructures obtained under different conditions and cavitation environment to compare the samples.

\subsection{Propeller Materials Used}

The materials used were $25 \times 25$-mm specimen samples of 2205 DSS and NAB with a thickness of $5 \mathrm{~mm}$ held under the horn with Perspex fixture for the indirect cavitation process. The surfaces of all the test samples were wet-polished using 1200 and 4000 grit silicon carbide ( $\mathrm{SiC}$ ) abrasive papers. Table 1 gives the mechanical properties of the ship propeller materials used for the experiment, and Table 2 gives the chemical compositions of the test materials used.

Ship propellers work in a very harsh environment under the sea, i.e. in a corrosive environment, for the majority of their lifetime. Hence, it is only reasonable for the chosen test materials to be based not only on their high tensile strength but also on their resistance to corrosion. DSS has been well known for its high resistance to intergranular corrosion, hence they serve as great raw material for building the propellers. DSS used for the experiment was type 2205. Mechanical properties were $774 \mathrm{MPa}$ ultimate tensile strength, $542 \mathrm{MPa}$ yield strength with $34 \%$ elongation and $233 \mathrm{Hv}$ Vickers hardness. The microstructure consisted of a ferritic matrix with islands of austenite grains as shown in Fig. 1. DSS displays properties characteristic of both austenitic and ferritic stainless steels due to their composite microstructure and are found to be, in most cases, tougher than ferritic SS and have higher strength as well as corrosion resistance as compared to the generally used engineering austenitic SS [27].

Similarly, NAB is another lightweight conventional ship propeller alloy used for the experiment for its high-strength mechanical properties with an ultimate tensile strength of $650 \mathrm{MPa}$, yield strength of $270 \mathrm{MPa}$ and $170 \mathrm{Hv}$ Vickers hardness. It is also considered to exhibit excellent cavitation resistance against the seawater [26]. NAB has high ability to retain its original smooth machined surface over a long period of time, thereby retaining its high efficiency factor, and it also has the ability to resist failure under impact when notched, contributing greatly to its value as a

Table 2 Chemical compositions of the materials used for the research

\begin{tabular}{lll}
\hline $\begin{array}{l}\text { Material alloys } \\
\text { composition (wt.\%) }\end{array}$ & $\begin{array}{l}\text { Nickel } \\
\text { aluminium bronze }\end{array}$ & $\begin{array}{l}\text { Duplex stainless } \\
\text { steel (2205) }\end{array}$ \\
\hline $\mathrm{C}(\%)$ & - & 0.024 \\
$\mathrm{Mn}(\%)$ & 1.07 & 1.83 \\
$\mathrm{Ni}(\%)$ & 4.73 & 5.66 \\
$\mathrm{Cr}(\%)$ & - & 22.7 \\
$\mathrm{Mo}(\%)$ & - & 3.01 \\
$\mathrm{Cu}(\%)$ & - & 0.22 \\
$\mathrm{Sn}(\%)$ & $<0.01$ & - \\
$\mathrm{Al}(\%)$ & 9.39 & - \\
$\mathrm{Pb}(\%)$ & 0.01 & - \\
$\mathrm{Zn}(\%)$ & 0.11 & - \\
$\mathrm{Fe}(\%)$ & 4.53 & - \\
$\mathrm{W}(\%)$ & - & 0.02 \\
$\mathrm{~N}(\%)$ & - & 0.02 \\
\hline
\end{tabular}

Table 1 Mechanical properties of the materials used for the research

\begin{tabular}{lllll}
\hline Propeller material alloys & $\begin{array}{l}\text { Ultimate tensile } \\
\text { strength }(\mathrm{MPa})\end{array}$ & $\begin{array}{l}\text { Yield } \\
\text { strength }(\mathrm{MPa})\end{array}$ & $\begin{array}{l}\text { Elongation } \\
(\%)\end{array}$ & $\begin{array}{l}\text { Density } \\
\left(\mathrm{g} / \mathrm{cm}^{3}\right)\end{array}$ \\
\hline 2205 (duplex stainless steel) & 774 & 542 & 34 & 7.8 \\
Nickel aluminium bronze (NAB) & 650 & 270 & 18 & 233 \\
\hline
\end{tabular}




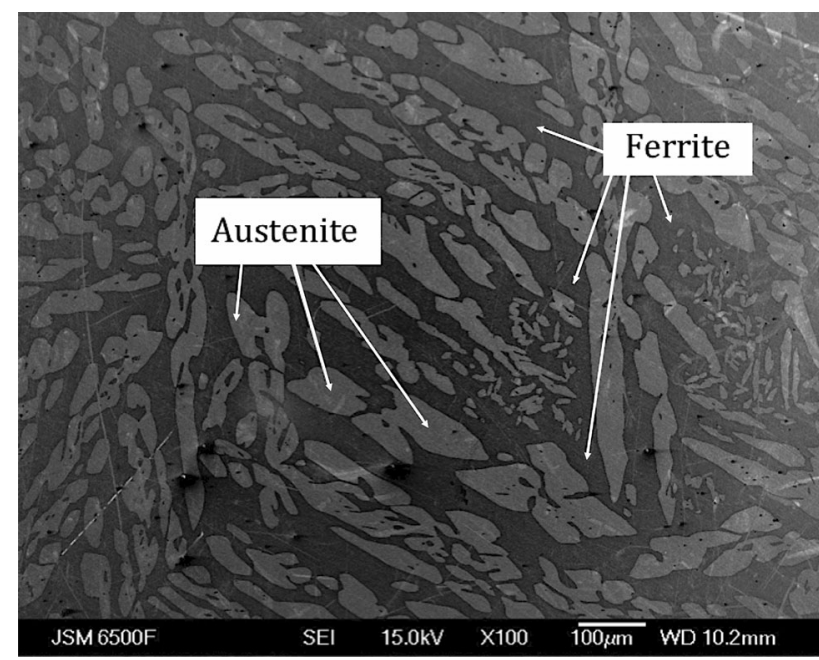

Fig. 1 SEM morphology of a two-phase microstructure of austenite and ferrite grains of 2205 duplex stainless steel

propeller material [26]. The microstructure of NAB is more complex than DSS with three distinct phases namely $\alpha, \beta$ and four forms of kappa ( $\kappa_{\mathrm{I}}, \kappa_{\mathrm{II}}, \kappa_{\mathrm{III}}$ and $\left.\kappa_{\mathrm{IV}}\right)$ in the as-cast microstructure. The microstructure generally consists of columnar grains of fcc copper-rich solid solution known as $\alpha$ phase and a small volume fraction of lamellar eutectoid phases $\beta^{\prime}$ phase or martensitic $\beta$ phase, surrounded by a series of intermetallic $k$ phases. The $\kappa_{\mathrm{I}}, \kappa_{\mathrm{II}}$ and $\kappa_{\mathrm{IV}}$ phases are all iron-rich precipitates distributed in the nickel aluminium structure. Among these intermetallic compounds, $\kappa_{I}$ phase is rosette-shaped precipitate formed at high temperatures in high-Fe content alloys and hence is coarser than the rest, $\kappa_{I I}$ phase is smaller than $k_{\mathrm{I}}$ phase and form a dendritic rosette shape which is distributed mostly at the $\alpha /$ $\beta$ boundaries; $\kappa_{\text {III }}$ phase is a fine lamellar "finger-like" eutectoid structure, forms at the boundary of $\kappa_{\mathrm{I}}$ phase and is rich in $\mathrm{Ni}$, and $\kappa_{\mathrm{IV}}$ phase is a fine Fe-rich cruciform- shaped precipitation of varying sizes with plate-like morphology that are distributed throughout the $\alpha$ grains along certain crystallographic directions forming within the $\alpha$ matrix beginning at $850 \mathrm{C}[26,28-30]$. The $\kappa_{I}$ and $\kappa_{I I}$ precipitates in the samples used for the experiment were found to be between 5 and $10 \mu \mathrm{m}$ and around $2 \mu \mathrm{m}$ in size, respectively. Figure 2 shows the SEM morphology of the $\mathrm{NAB}$ microstructure used in the experiment.

\subsection{Cavitation Erosion Measurements}

The first test conducted was the pure erosion test. The samples were cavitated in $5 \mathrm{~L}$ of stagnant distilled water for $1 \mathrm{~h}$ at a frequency of $20 \mathrm{kHz}$ and a peak-to-peak amplitude of 80 micron. The samples were kept at a constant distance of $2 \mathrm{~mm}$ away from the sonotrode tip. The temperature and $\mathrm{pH}$ of the water were monitored before and after the experiment, starting from room temperature and a $\mathrm{pH}$ of 8.9. Weight of the sample was recorded both before and after each experiment with a precision weighing machine. The samples were then analysed under Alicona and Talysurf to obtain the surface roughness, maximum depth of penetration, volume loss and the subsequent volumetric mass loss incurred.

\subsection{Electrochemical Measurements}

For the erosion-corrosion test the samples were cavitated in 5 litres of $3.5 \% \mathrm{NaCl}$ salt water while kept under OCP for 1 hour with exactly the same electrochemical arrangements as for pure corrosion (as shown in Fig. 3). The samples were kept at OCP for $1 \mathrm{~h}$ in $5 \mathrm{~L}$ of $3.5 \% \mathrm{NaCl}$ solution where $\mathrm{Ag} / \mathrm{AgCl}$ was used as the reference electrode, sample as the working electrode and graphite rod as the counter electrode.
Fig. 2 Microstructural morphology of $\mathrm{Cu} 3$ cast-NAB at a magnification of $100 \mathrm{x} . k_{\mathrm{II}}$ is the globular dendritic structure, $k_{\text {III }}$ is the lamellar "finger-like" structure and $k_{\mathrm{IV}}$ is the very fine particulate imbedded within the alpha matrix (surrounding phase)

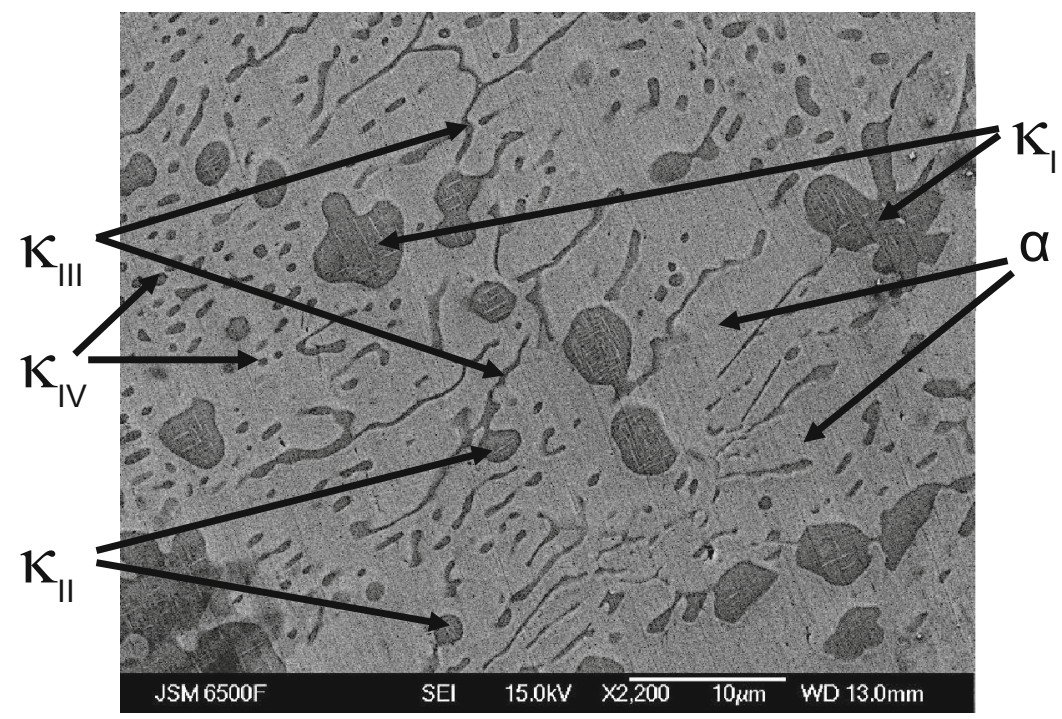


Fig. 3 Schematics of the cavitation rig with specimen under cavitation erosioncorrosion

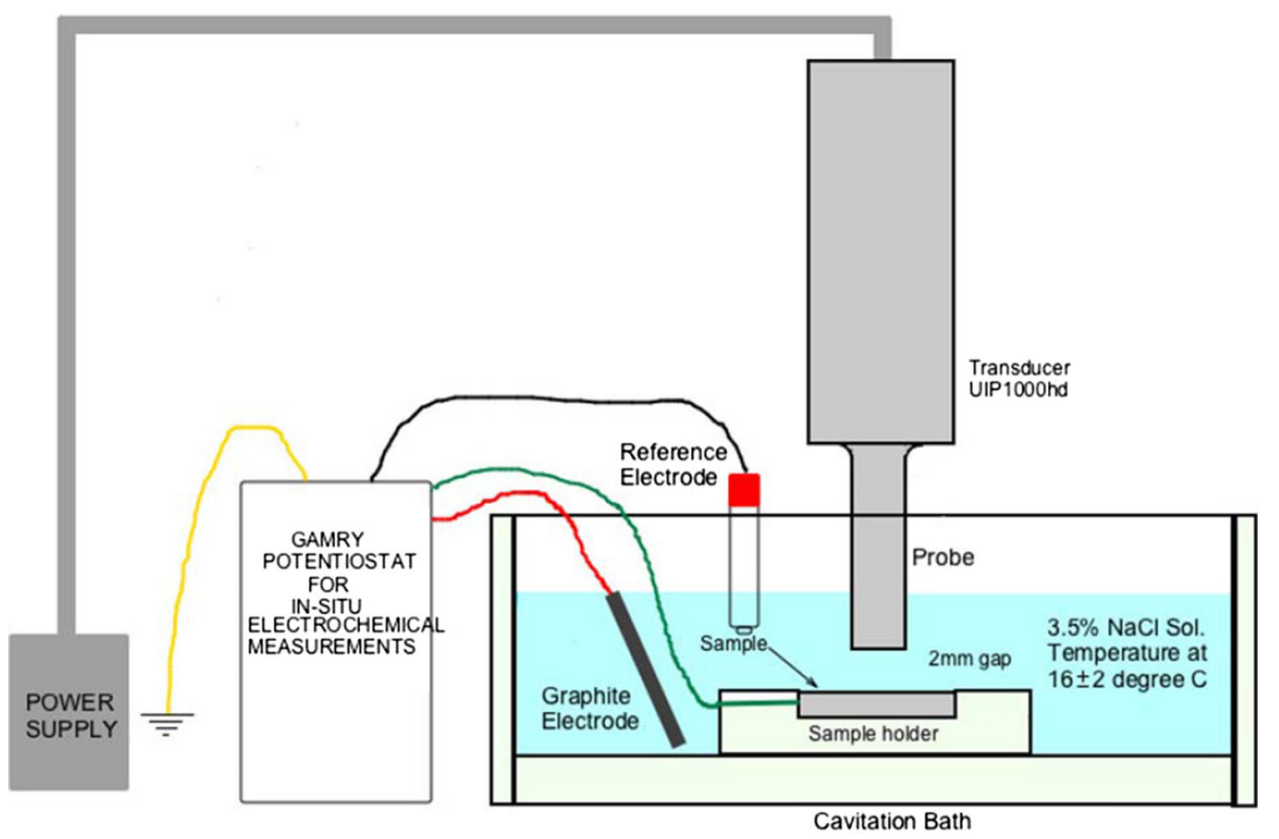

For the erosion-corrosion test, the samples were cavitated in $5 \mathrm{~L}$ of $3.5 \% \mathrm{NaCl}$ salt water while kept under OCP for $1 \mathrm{~h}$ with exactly the same electrochemical arrangements as for pure corrosion (as shown in Fig. 3). The corrosion test preceded cavitation test by $10 \mathrm{~min}$, and after 10 min the cavitation rig was switched on. The nature and properties of the sample materials as well as the corrosion products, formed in a corrosive environment, and the effects of cavitation determine the behaviour of the sample alloys as well as help characterize them.

\section{Results and Discussions}

For the erosion and erosion-corrosion test the concentric rings of cavitated and non-cavitated regions were formed around a centrally damaged area. This phenomenon could be attributed to the natural resonant frequency of the probe and probe tip itself. The total cavitated diameter was measured to be $15 \mathrm{~mm}$ across for both the materials as can be seen in Fig. 4. There was a gradual increase in the temperature of the liquid medium from $16-17^{\circ} \mathrm{C}$ to $22{ }^{\circ} \mathrm{C}$ after cavitation; however, $\mathrm{pH}$ remained almost the same throughout the entirety of the experiments, i.e. between 8.5 and 9. This temperature rise could help enhance electrochemical reaction on the samples.

\subsection{Surface Profilometry and Morphology}

The surface profilometry and average roughness $\left(R_{\mathrm{a}}\right)$ and MDP of each sample after each test were measured using Alicona and Talysurf. Figure 5 shows the surface

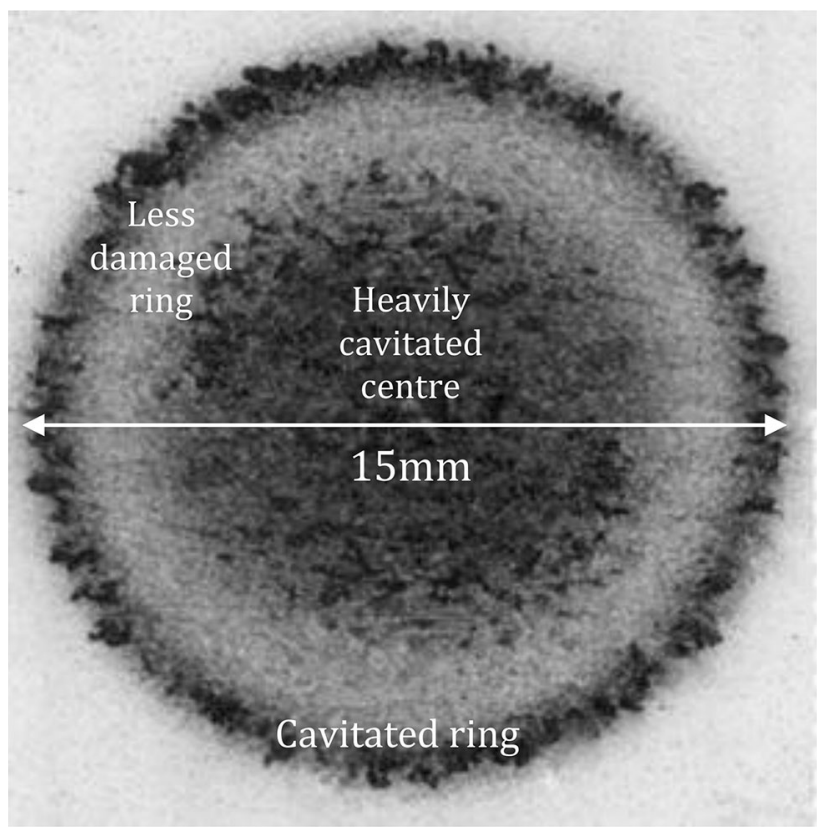

Fig. 4 The cavitated surface of DSS

roughness and individually labelled damage regions of DSS sample after undergoing cavitation in distilled water obtained using Talysurf, which was employed to obtain the surface roughness across the diameter of the samples.

Alicona was also employed to measure the volume loss for each sample post cavitation. Table 3 tabulates the measured values of $R_{\mathrm{a}}, \mathrm{MDP}$ and volume loss for NAB and DSS under each condition.

The SEM morphologies of NAB and DSS under distilled water as well as $3.5 \% \mathrm{NaCl}$ solution are shown in Fig. 6. 


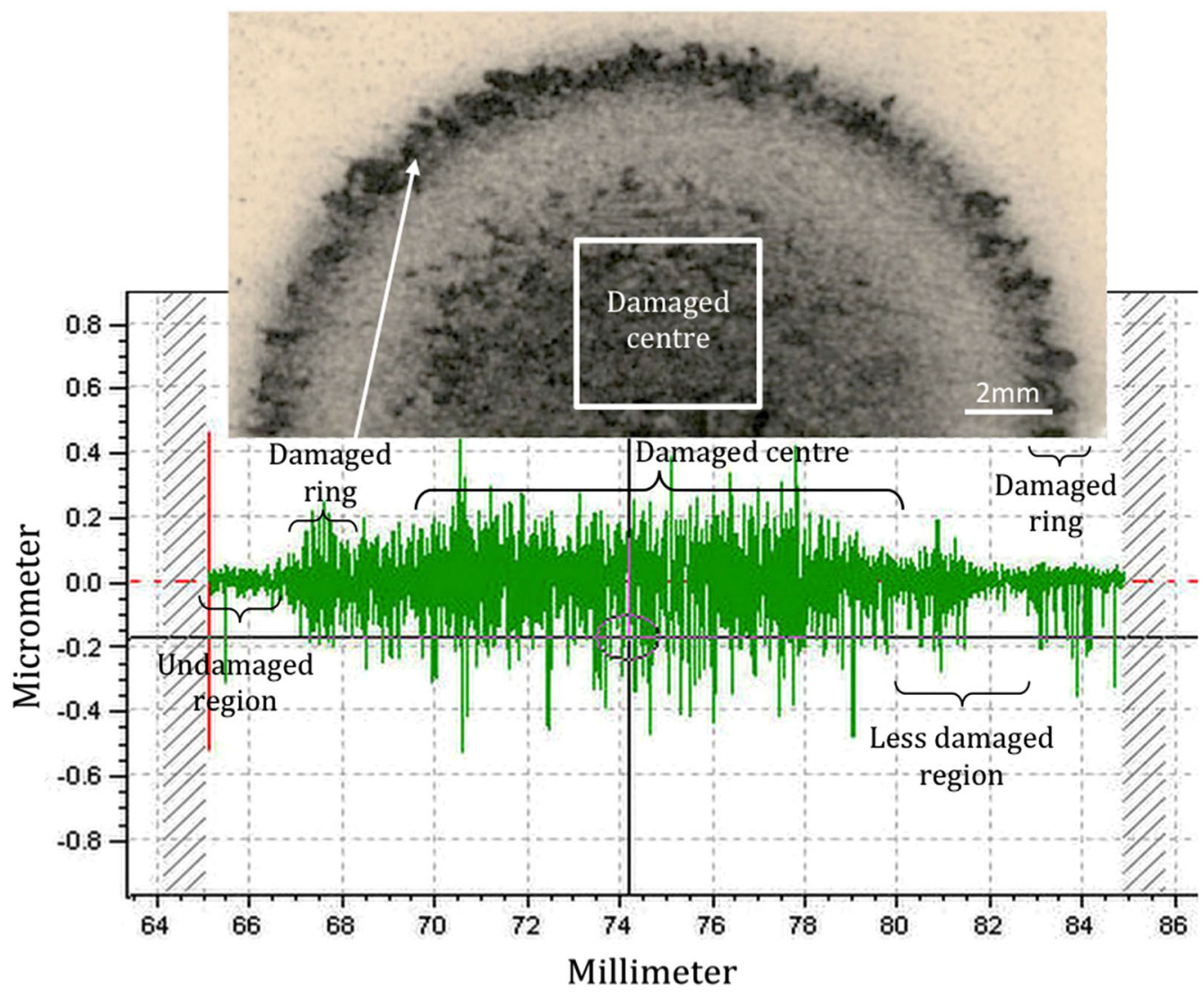

Fig. 5 Talysurf surface roughness profilometry at the centre of the cavitated surface of DSS in distilled water

Table 3 Average roughness, mean depth of penetration and volume loss measured using Alicona

\begin{tabular}{|c|c|c|c|c|c|c|c|}
\hline \multirow[t]{2}{*}{ Material used } & \multicolumn{3}{|c|}{ Average surface roughness $(\mathrm{nm})$} & \multicolumn{2}{|c|}{ Mean depth of penetration (nm) } & \multicolumn{2}{|c|}{ Measured volume loss $\left(\mathrm{mm}^{3}\right)$} \\
\hline & $\begin{array}{l}\text { Uncavitated } \\
\text { surface }\end{array}$ & $\begin{array}{l}\text { Distilled } \\
\text { water }\end{array}$ & $\begin{array}{l}3.5 \% \\
\mathrm{NaCl} \text { sol. }\end{array}$ & $\begin{array}{l}\text { Distilled } \\
\text { water }\end{array}$ & $\begin{array}{l}3.5 \% \\
\mathrm{NaCl} \text { sol. }\end{array}$ & $\begin{array}{l}\text { Distilled } \\
\text { water }\end{array}$ & $\begin{array}{l}3.5 \% \\
\mathrm{NaCl} \text { sol. }\end{array}$ \\
\hline Nickel aluminium Bronze & 49 & 153 & 165 & 645 & 955 & 0.115 & 0.169 \\
\hline Duplex stainless Steel & 52 & 113 & 163 & 460 & 598 & 0.081 & 0.106 \\
\hline
\end{tabular}

Figure 6a, e shows the general microstructures of NAB and DSS, respectively, where Fig. 6a exhibits the lighter $\alpha$ phase with dark dendritic intermetallic kappa phases distributed in the copper-rich $\alpha$ matrix and many visible Ferich $\kappa_{I}$ and $\kappa_{I I}$ precipitates around the boundaries. Interfaces between the matrix, intermetallic and grain boundaries are generally the weak points in the microstructure of metallic materials that are more likely to be attacked by the cavitation. Figure $6 \mathrm{~b}$ shows the morphology of NAB under cavitation in distilled water. Small cavities of sizes 10-30 $\mu \mathrm{m}$ were found especially in grain boundaries as it was established that the material surface underwent selective cavitation at the $\alpha-\kappa$ phase boundaries. The $\kappa$ precipitates and precipitate-free $\alpha$ zones did not suffer any visible cavitation after $1 \mathrm{~h}$ of cavitation test in distilled water. For the cavitation erosion-corrosion test, the cavities were recorded to be much larger, 50-80 $\mu \mathrm{m}$, and the sample surface had visible corrosion products. Figure $6 \mathrm{~d}$ is the magnified $(20,000 \times)$ image of one of the cavities on $\mathrm{NAB}$ tested under $3.5 \% \mathrm{NaCl}$ salt solution with spheres of silicon and aluminium oxides visible in the cavity. Large cavity was observed with globules of oxides formed in these cavities along with ductile tearing and corrosion of the boundaries of the $\alpha$ columnar grains as seen in Figure 6d. Many factors could cause the results obtained such as the softer composition of the cu-rich $\alpha$ phase as compared to much harder iron-rich intermetallic precipitates; it could be expected for the $\alpha$ phase to be more susceptible to cavitation erosion. There were also grainboundary attacks observed which could indicate that electrochemical dissolution within the structure may contribute in the cavitation damage. Another reason for the selective 
Fig. 6 a General

microstructure of NAB at $\times 100$ magnification, $\mathbf{b}$ cavitated region of NAB under distilled water after $1 \mathrm{~h}$ of exposure, c cavitated region of $\mathrm{NAB}$ under $3.5 \% \mathrm{NaCl}$ solution, $\mathbf{d} \times 20,000$ magnified cavitated region of $\mathrm{NAB}$; e general microstructure of DSS, $\mathbf{f}$ cavitated region of DSS under distilled water after $1 \mathrm{~h}$ of exposure, $\mathbf{g}$ cavitated region of DSS under $3.5 \%$ $\mathrm{NaCl}$ solution, $\mathbf{h} \times 960$ magnified cavitated region of DSS in $3.5 \% \mathrm{NaCl}$ solution
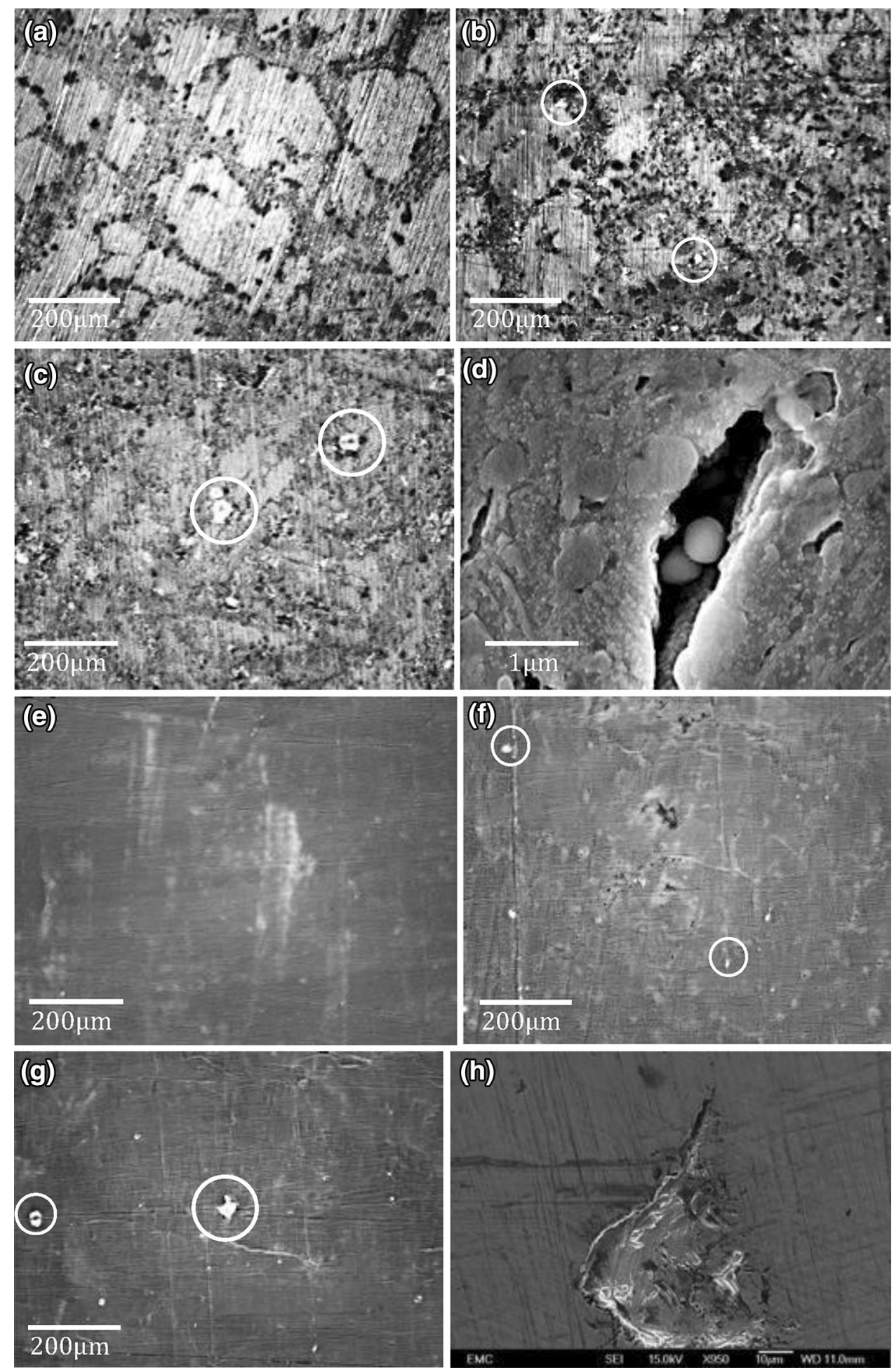

attack may be due to the cathodic behaviour of Fe-rich phase when compared with the $\alpha$ phase which may induce galvanic corrosion. This conclusion is found consistent with the findings of previous works [26, 31-33].

As for DSS, the morphologies of DSS under both distilled water and salt solution were almost same with no visible corrosion product. However, on comparing the cavity sizes, the cavities under $3.5 \%$ salt solution were almost five times the size of that under distilled water, see Fig. 6f, g. On taking a closer look under SEM, it was seen that the cavitation attack was rather selective, with cavities attacking the ferritic matrix and the ferrite-austenite 
boundaries. Figure $6 \mathrm{~h}$ shows a $40 \times 70$ - $\mu \mathrm{m}$-large cavity formed in DSS under the salt solution where ductile failure can be seen in the form of extrusion of the austenite at the cavity boundary visible in Fig. 7. Also visible are tiny microcracks and cleavage-like facets that may have been caused by the austenite-to-martensite transformation either due to high strain or due to the high temperature accredited to cavitation. This result holds consistent with the findings of the study by Al-Hashem and Riad [34].

\subsection{Electrochemical Results}

Figure 8 is the OCP curve obtained for DSS and NAB in pure corrosion and erosion-corrosion in $3.5 \% \mathrm{NaCl}$ solution. All the tests were conducted for $1 \mathrm{~h}$. For the cavitation erosion-corrosion tests, the cavitation rig was switched on after $600 \mathrm{~s}$ to obtain the change in the

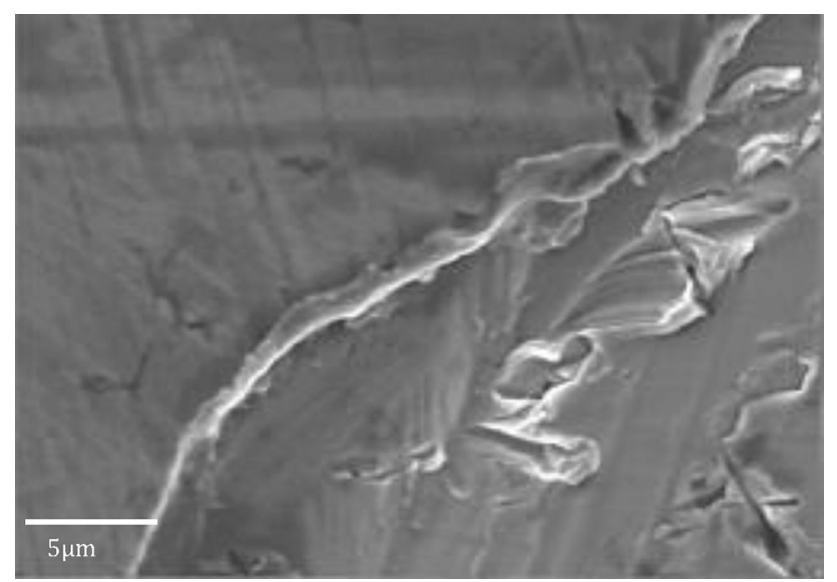

Fig. 7 SEM images of plastic deformation at cavitation-damaged edge for DSS in distilled water electrochemical behaviour of the sample materials. As can be seen from the trend, there was a negative shift of OCP from -70 to $-500 \mathrm{mV}$. However, DSS was seen to attain stability within $10 \mathrm{~min}$ at a lower voltage, and this OCP shift can be attributed to the result of protective oxide layer destroyed by cavitation erosion. Similarly, the trend for NAB shifted to negative when the rig was turned on, but it attained stability much quicker than DSS (within 100 s) at a lower potential than that under pure corrosion. On comparing the OCP trend of the two materials when undergoing cavitation, it can be seen that while NAB reaches stability at $-210 \mathrm{mV}$ at a lower voltage as compared to DSS, the stability of DSS attained after the rig is switched on is much lower than that of NAB showing that NAB has higher corrosion resistance than DSS. Similar to the results observed by Al-Hashem et al. [24], there was a shift in corrosion potential for DSS under cavitation in the active direction by $75 \mathrm{mV}$; however, there was not a very substantial shift in case of NAB. This may be due to the experimental reproducibility since several tests were conducted giving similar results.

Figure 9 shows the electrochemical impedance spectra (EIS) graph for the DSS and NAB samples with and without cavitation. From the figure, it can be seen that both the samples show very good resistance to corrosion both with and without cavitation. Although it is clear that the impedance was higher for DSS in saltwater alone without cavitation as compared to DSS undergoing cavitation erosion-corrosion, it was seen that the impedance of NAB under corrosion was slightly lower than that under cavitation erosion-corrosion. The reason for the high resistance to corrosion may be explained from Fig. 10a, b, where it can be seen that a high percentage of chromium was present in the chemical composition of DSS, and also a high

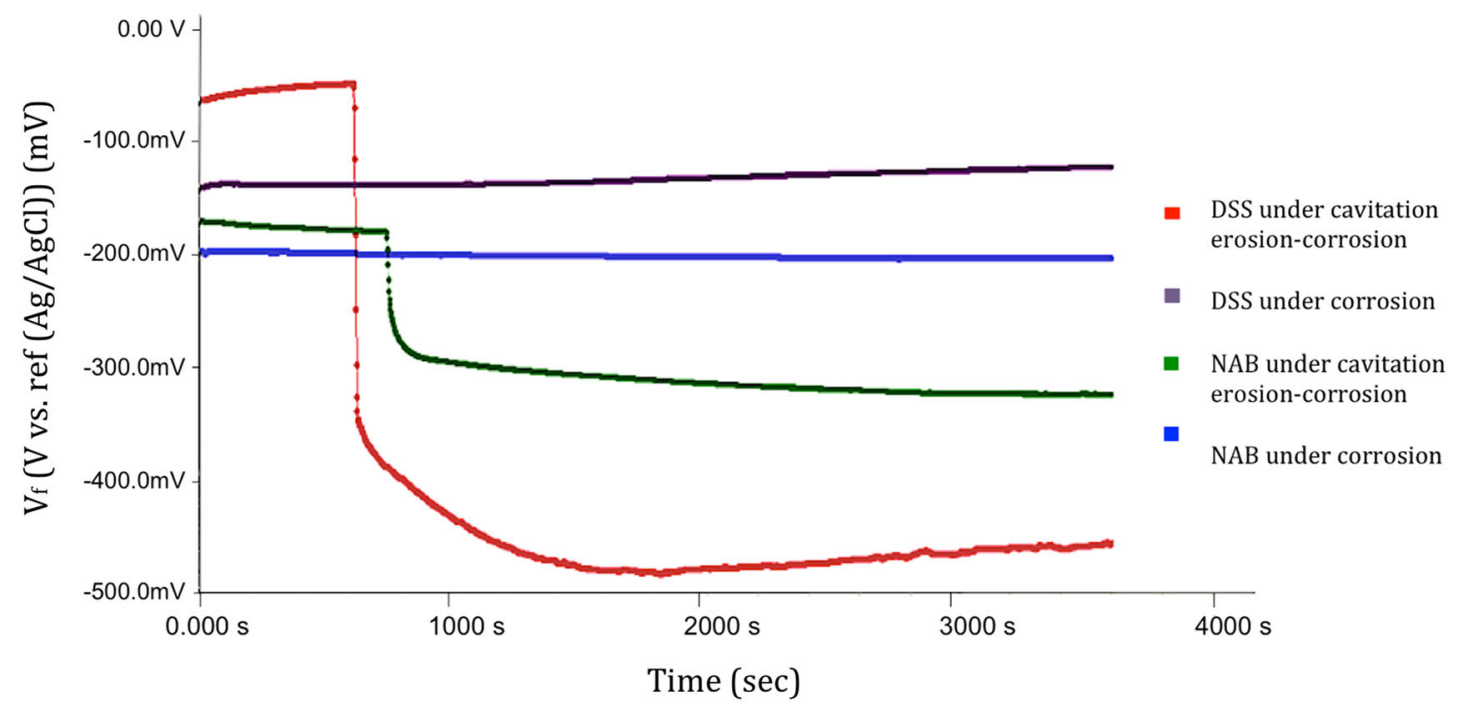

Fig. 8 OCP for DSS and $\mathrm{NAB}$ in $3.5 \% \mathrm{NaCl}$ solution for $1 \mathrm{~h}$ with and without cavitation 
percentage of silicon and aluminium oxides were formed on the surface of NAB. However, while DSS is highly corrosion resistant with a passive layer of iron oxide as well as chromium oxide forming to protect the surface from corrosion, the film thickness is in the range of $2 \mathrm{~nm}$
[35]; whereas a passive layer of oxides forms in case of NAB that has a film thickness of $900-1000 \mathrm{~nm}$ [36]; this was further verified on taking EDX spectrum of cavitated NAB surface under distilled as well as $3.5 \% \mathrm{NaCl}$ solution, which indicated the presence of silicon $\left(\mathrm{SiO}_{2}\right)$ and

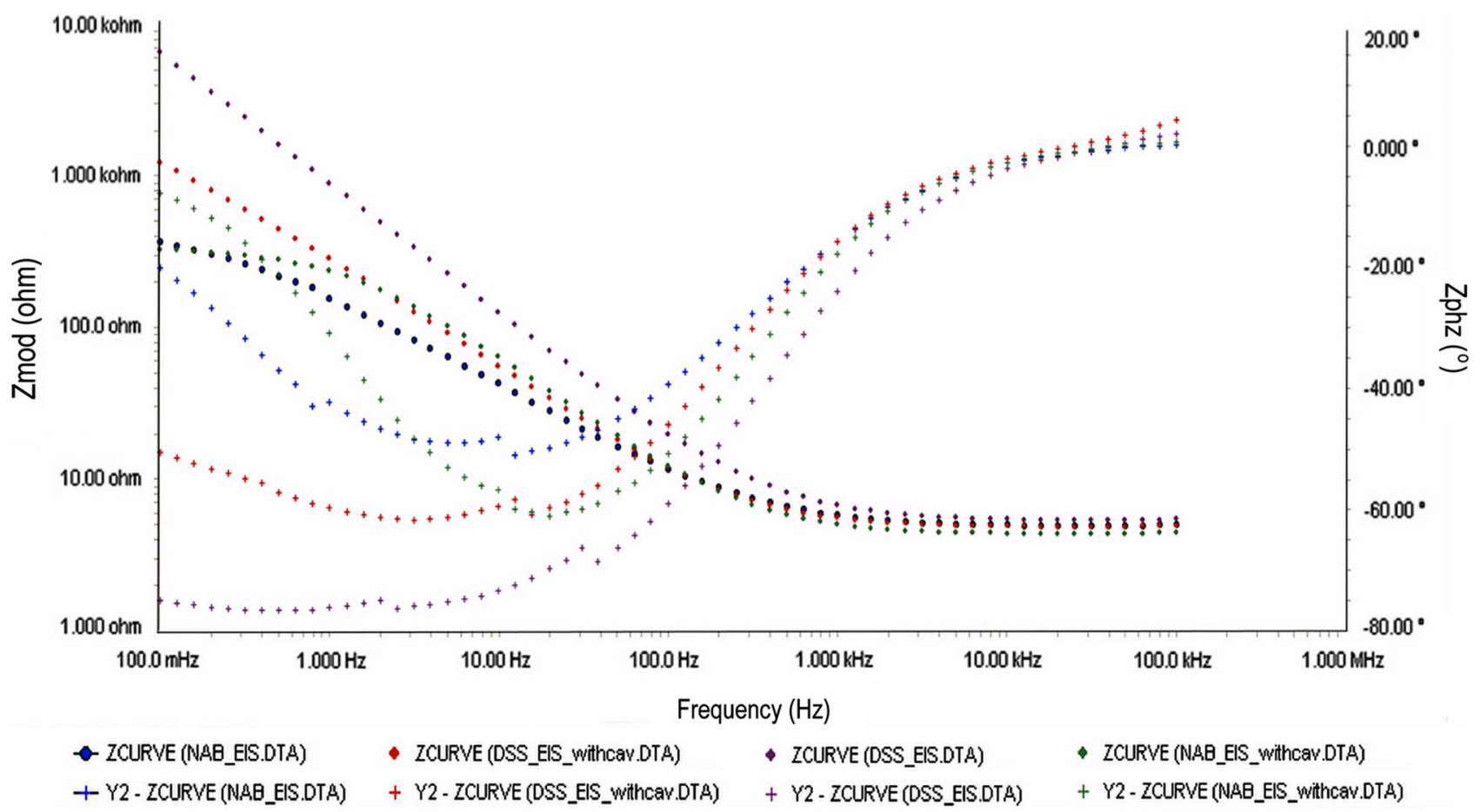

Fig. 9 EIS for DSS and $\mathrm{NAB}$ in $3.5 \% \mathrm{NaCl}$ solution with and without cavitation

(a)

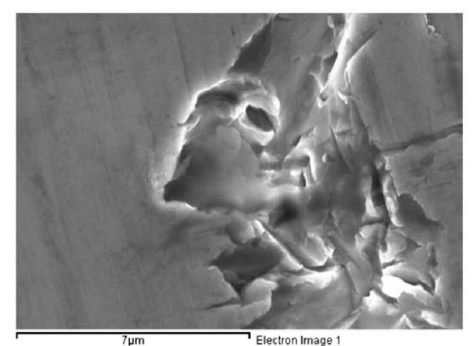

Standard:

$\mathrm{Cr} \mathrm{Cr}$

$\mathrm{Fe} \mathrm{Fe}$

\begin{tabular}{l|ll}
\hline Element & Weight\% & Atomic\% \\
& & \\
$\mathrm{Cr} \mathrm{K}$ & 23.05 & 24.34 \\
$\mathrm{Fe}$ & 76.95 & 75.66 \\
& & \\
Totals & 100.00 & \\
\hline
\end{tabular}

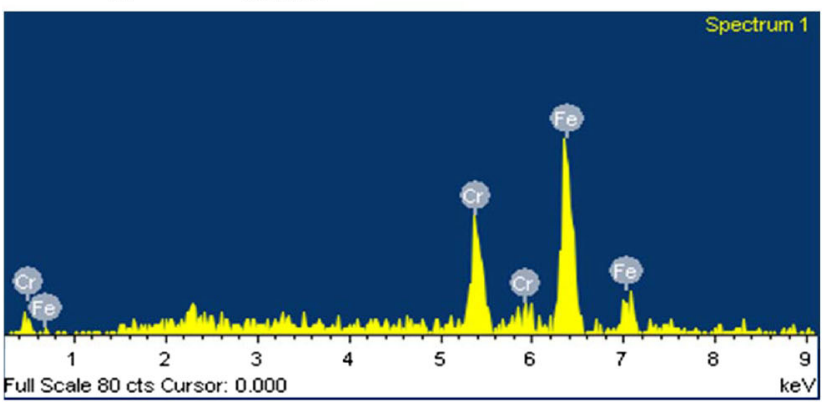

(b)

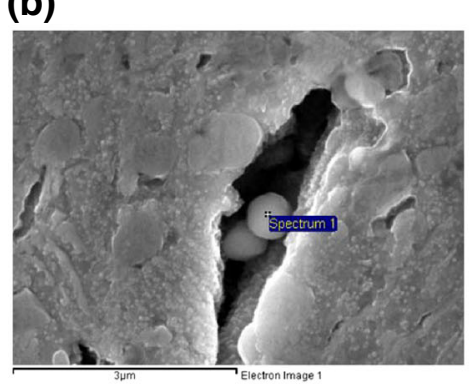

Standard:

o $\mathrm{SiO2}$

$\begin{array}{lll}\text { Al } & \text { Al203 } \\ \text { Pe } & \text { Fe } & \end{array}$

$\mathrm{Fe} \mathrm{Fe}$

$\mathrm{Ni} \mathrm{Ni}$

$\mathrm{Cu} \mathrm{Cu}$

Element $\mid$ Weight $\%$ Atomic\%

\begin{tabular}{l|ll} 
& & \\
$\mathbf{0}$ & $\mathbf{1 . 4 9}$ & $\mathbf{4 . 5 2}$ \\
$\mathrm{Al} \mathrm{K}$ & 16.04 & 28.92 \\
$\mathrm{Fe}$ & 13.18 & 11.48 \\
$\mathrm{Ni}$ & 32.19 & 26.68 \\
$\mathrm{Cu} \mathrm{L}$ & 37.10 & 28.41 \\
& & \\
Totals & 100.00 & \\
\hline
\end{tabular}

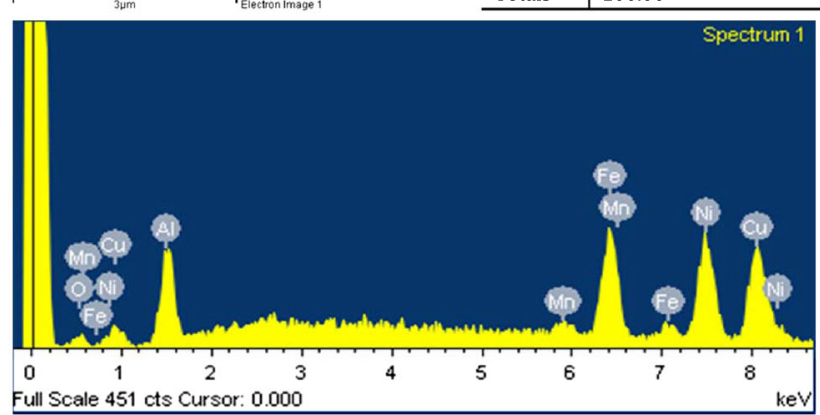

Fig. 10 EDS spectrum of a DSS cavitated under $3.5 \% \mathrm{NaCl}$ solution and b $\mathrm{NAB}$ cavitated under $3.5 \% \mathrm{NaCl}$ solution 
aluminium oxides $\left(\mathrm{Al}_{2} \mathrm{O}_{3}\right)$, see Fig. $10 \mathrm{~b}$. These may account for the high corrosion resistance of both the material samples used.

\subsection{Synergy Calculation}

From Table 3, the value of volumetric mass loss for each sample was extracted using the simple mass, volume and density formula:

Density $=$ mass/volume,

where density of $\mathrm{NAB}=7.65 \mathrm{~g} / \mathrm{cm}^{3}$ and density of DSS $=7.8 \mathrm{~g} / \mathrm{cm}^{3}$. Hence, the following values are tabulated in Table 4 in order to compare the mass loss obtained using precision weighing machine and Alicona. The mass change observed during pure corrosion was mass gain rather than mass loss, hence it is considered negative since mass loss is considered positive.

From the pure corrosion measurements shown in Table 4 and Eq. 3, the thickness of the passive layer formed on the sample surface was calculated. The oxide layers consisting predominant of $\mathrm{Al}_{2} \mathrm{O}_{3}$ in case of $\mathrm{NAB}$ and $\mathrm{Cr}_{2} \mathrm{O}_{3}$ in case of DSS were found to be of thickness $0.24 \mu \mathrm{m}$ and $0.03 \mu \mathrm{m}$, respectively.

Using Eqs. 1 and 2, and considering the values of gravimetric mass loss from Table 4, the synergy can be calculated and the values are tabulated in Table 5.

\subsection{Discussion}

It can be seen from Table 5 that for both NAB and DSS synergy has measurable impact on their cavitation erosioncorrosion. While the synergy between cavitation erosion and corrosion for NAB was found to be $73.6 \%$, it is almost half in case of DSS at $36.5 \%$, with $\Delta C$ (erosion-enhanced corrosion) dominating the synergy result for both cases. These values are in general much higher when compared with the synergy results obtained by other studies. The study by Neville, Hodgkiess and Dallas [37] found the synergy for 2205 DSS eroded under liquid-solid jet impingement under saline solution to be about $20 \%$, whereas the vibratory cavitation as well as hydrodynamic cavitation erosion-corrosion synergy tests conducted by Wood and Hutton [38] showed $S / T \%$ values to be in the range of $30 \%$ to $>60 \%$ for various materials tested under $3 \% \mathrm{NaCl}$ solution such as grey cast iron, 1020 mild steel, 304 SS and copper alloys. Several engineering alloys tested in $3.5 \% \mathrm{NaCl}$ solution by Kwok et al. [39] showed very low (negligible) $S / T \%$ of damage for corrosion-resistant materials such as 316 SS, 304 SS and Zeron 100 super DSS. However, it must be noted that these studies were carried out with varying conditions, and also most of these studies considered rate of depth of penetration as their means of calculating synergy.

One reason for the existence of synergy could be due to the difference in the quantity of dissolved gases present in each medium. While $3.5 \% \mathrm{NaCl}$ solution may have higher amount of dissolved oxygen, it also has dissolved minerals and radicals among other such factors that can affect the bubble nucleation, growth and impact. Distilled water is considered to have negligible amount of dissolved minerals, and hence cavitation impact and results obtained in distilled water can vary significantly from that in $3.5 \%$ $\mathrm{NaCl}$ solution. Also, few anomalies may exist due to certain assumptions made during the experiment such as, the erosion test without any external electrochemical application was considered as pure erosion test; however, there was still a small level of corrosion taking place in the form of passivity of the individual materials itself. This alone may explain the difference in the mass change between the two materials for pure erosion test when comparing gravimetric with volumetric analyses. One way of immunizing the material from any corrosion could be by using the $\mathrm{pH}$ of the solution to move the material to immune section of pourbaix diagram in order to protect it from

Table 4 Comparison between gravimetric mass loss and volumetric mass loss

\begin{tabular}{|c|c|c|c|c|c|}
\hline \multirow[t]{2}{*}{ Material used } & \multicolumn{2}{|c|}{$\begin{array}{l}\text { In distilled water cavitation erosion loss } \\
(E)\end{array}$} & \multicolumn{2}{|c|}{$\begin{array}{l}\text { In } 3.5 \% \mathrm{NaCl} \text { solution cavitation erosion-corrosion } \\
\text { loss }(T)\end{array}$} & \multirow{2}{*}{$\begin{array}{l}\text { Pure corrosion } \\
\text { mass gain } \\
(C)(\mathrm{mg})\end{array}$} \\
\hline & $\begin{array}{l}\text { Gravimetric } \\
\text { mass loss (in mg) }\end{array}$ & $\begin{array}{l}\text { Volumetric mass } \\
\text { loss (in mg) }\end{array}$ & $\begin{array}{l}\text { Gravimetric mass } \\
\text { loss (in mg) }\end{array}$ & $\begin{array}{l}\text { Volumetric mass } \\
\text { loss (in mg) }\end{array}$ & \\
\hline Nickel aluminium bronze & 1.00 & 0.88 & 1.48 & 1.29 & -0.61 \\
\hline Duplex stainless steel & 0.71 & 0.63 & 0.96 & 0.82 & -0.10 \\
\hline
\end{tabular}

Table 5 Synergism summary for the samples

\begin{tabular}{llllll}
\hline Material used & $T(\mathrm{mg})$ & $E(\mathrm{mg})$ & $C(\mathrm{mg})$ & $S=T-(E+C)(\mathrm{mg})$ & $(S / T) \times 100(\%)$ \\
\hline Nickel aluminium bronze & 1.48 & 1.00 & -0.61 & 1.09 & 73.6 \\
Duplex stainless steel & 0.96 & 0.71 & -0.10 & 0.35 & 36.5 \\
\hline
\end{tabular}


corrosion. Also, instead of using distilled water, cathodic protection can also be employed to prevent the samples from corrosion; however, while cathodic protection can prevent corrosion, it is difficult to suppress corrosion and hydrogen evolution simultaneously as also explained by Kwok et al. [39]. Hydrogen could cause embrittlement in stainless steels, but it may also exert a cushioning effect, reducing mechanical erosion, and this may potentially increase the relative contribution of synergism.

For the synergy result, gravimetric mass loss values were considered due to the reason that, although both gravimetric as well as volumetric mass loss measurements are useful and efficient in their own account, they both have major shortcomings. While the data obtained using precision weighing machine can be considered accurate, several factors may affect the results, such as sediments of eroded titanium probe tip deposited on the sample, dissolved $\mathrm{NaCl}$ salt deposits and absorption of water by porous layers/coats if any, as well as other impurities that cannot be detected and fully prevented. Also, as the samples are introduced to a corrosive environment, if they are highly corrosive and form corrosion product immediately after erosion, it is hard to tell how much mass is actually lost accurately. The mass balance does not take into account these factors, and this could cause deviation in the final result. On the other hand, volumetric analyses using Alicona can be equally crude since the highest magnification achievable using Alicona is $100 \times$, which may sometimes cause loss of data while looking at very smooth and reflective surface, or due to reentrant topography of the surface. Also, in case that there are sediments, corrosion products, micro scratches and burrs existing on the sample surface, Alicona cannot differentiate and do selective volume loss, which again causes deviation from the result. It may also manifest its own roughness and waviness of the surface when using lower magnification or highly reflective surface, which was applicable for the experiments undertaken. Due to this, gravimetric analyses were slightly more preferable.

\section{Conclusion}

From the experiments conducted, it can be concluded that after a short period of exposure to cavitation both NAB and DSS have measurably high synergistic effect under cavitation erosion-corrosion. In the case of NAB, the synergy between cavitation wear and corrosion was found to be $73.6 \%$ and for DSS it was found to be $36.5 \%$. The data obtained from electrochemical measurement for the cavitation erosion-corrosion test showed that, although duplex SS exhibited higher resistance to corrosion under seawater alone, NAB exhibited much higher resistance to corrosion when subjected to cavitation. Also, NAB attained stability much faster and at higher potential than DSS, proving that it is more corrosion resistant.

The NAB surface was seen to undergo selective cavitation erosion-corrosion attack at the $\alpha$ phase and the $\alpha-\kappa$ phase boundaries with ductile deformation around the cavity, while the $\kappa$ precipitates and precipitate-free $\alpha$ zones were found to suffer no visible cavitation after $1 \mathrm{~h}$ of cavitation test in both distilled water as well as $3.5 \% \mathrm{NaCl}$. The DSS was seen to undergo ductile failure in the cavitated zone in the form of extrusion of the austenite at the cavitation pit along with microcracks and cleavage facets that could be attributed to the austenite-to-martensite transformation by either the high strain rate or high temperatures generated during cavitation. And because of that the erosion process was found to be predominantly of plastic nature with little of no fatigue failure noticed at this stage, due to this NAB was found to be more susceptible to erosion under both the conditions as compared to duplex SS with prominent selective cavitation erosion of alpha phase in the microstructure since DSS is harder than NAB. From the experiments conducted, it was concluded that synergy had measurable impact on the cavitation erosioncorrosion of both $\mathrm{NAB}$ and duplex SS, and the overall synergy for $\mathrm{NAB}$ was found to be higher than that for DSS.

Conflict of interest None.

\section{References}

1. Vyas B, Hansson ILH (1990) The cavitation erosion-corrosion of stainless steel. Corros Sci 30(8): 761-770

2. Engelberg G, Yahalom J, Kalir E (1985) Observations on the cavitation of steels. Corros Sci 25(10) 871-882

3. Tomlinson WJ, Talks MG (1991) Erosion and corrosion of cast iron under cavitation conditions. Tribol Int 24:67

4. Wood RJK, Fry SA (1989) The synergistic effect of cavitation erosion and corrosion for copper and Cupro-Nickel in seawater. J Fluids Eng 111(3):271

5. Kwok C, Man H, Cheng F(1998) Cavitation erosion and damage mechanisms of alloys with duplex structures. Mater Sci Eng A 242(1-2):108-120

6. Kwok CT, Man HC, Cheng FT (1998) Cavitation erosion of duplex and super duplex stainless steels. Scr Mater 39(9): 1229-1236

7. Zheng Y, Luo S, Ke W (2007) Effect of passivity on electrochemical corrosion behavior of alloys during cavitation in aqueous solutions. Wear 262(11-12):1308-1314

8. Kwok CT, Man HC, Leung LK (1997) Effect of temperature, $\mathrm{pH}$ and sulphide on the cavitation erosion behaviour of super duplex stainless steel. Wear 211(1):84-93

9. Luo SZ, Zheng YG, Li MC, Yao ZM, Ke W (2003) Effect of cavitation on corrosion behavior of 20SiMn low-alloy steel in 3\% sodium chloride solution. Corrosion 59(7):597-605

10. Kwok C, Cheng F, Man H (2000) Synergistic effect of cavitation erosion and corrosion of various engineering alloys in $3.5 \% \mathrm{NaCl}$ solution. Mater Sci Eng A http://linkinghub.elsevier.com/retrieve/ pii/S0921509300008996 
11. Yu H, Zheng YG, Yao ZM (2006) The cavitation erosion and erosion-corrosion behavior of carbon steel in simulating solutions of three rivers of China. Mater Corros 57(9):705-714

12. Sakamoto A, Funaki H, Matsumura M (2000) Seminar influence of galvanic macro-cell corrosion on the cavitation erosion durability. Int cavitation Eros test Semin

13. Thiruvengadam A, Waring SJ (1966) Mechanical properties of metals and their cavitation damage resistance. J Ship Res 10:1-9

14. Kwok C, Man H, Cheng F (2001) Cavitation erosion-corrosion behaviour of laser surface alloyed AISI 1050 mild steel using NiCrSiB. Mater Sci Eng A 303(1-2):250-261

15. Kwok CT, Cheng FT, Man HC Cavitation erosion and corrosion behaviors of laser-aluminized mild steel. Surf Coat Technol 200(11):3544-3552

16. Man HC, Kwok CT, Yue TM (2000) Cavitation erosion and corrosion behaviour of laser surface alloyed MMC of $\mathrm{SiC}$ and Si3N4 on Al alloy AA6061. Surf Coat Technol 132(1):11-20

17. Kwok C, Man H, Cheng F (2000) Cavitation erosion and pitting corrosion behaviour of laser surface-melted martensitic stainless steel UNS S42000. Surf Coat Technol 126(2-3):238-255

18. Kwok CT, Man HC, Cheng FT (1998) Cavitation erosion and pitting corrosion of laser surface melted stainless steels. Surf Coat Technol 99(3):295-304

19. Shifler DA (2005) Understanding material interactions in marine environments to promote extended structural life. Corros Sci 47(10):2335-2352

20. Stack MM, Jana BD (2004) Modelling particulate erosion-corrosion in aqueous slurries: some views on the construction of erosion-corrosion maps for a range of pure metals. Wear 256(9-10):986-1004

21. Stack MM, Corlett N, Zhou S (1997) A methodology for the construction of the erosion-corrosion map in aqueous environments. Wear 203:474-488

22. Wood RJK (2006) Erosion-corrosion interactions and their effect on marine and offshore materials. Wear 261(9):1012-1023

23. Richman RH, Mcnaughton WP (1990) Correlation of cavitation properties of metals erosion behavior with mechanical. Wear 140:63-82

24. Al-Hashem A, Caceres PG,Abdullah A, Shalaby HM (1997) Cavitation corrosion of duplex stainless steel in Seawater. Corrosion 53(2):103-113
25. Al-Hashem A, Caceres PG, Riad WT, Shalaby HM (1995) Cavitation corrosion behavior of cast nickel-aluminum bronze in seawater. Corrosion 51(5):331-342

26. Al-Hashem A, Riad W (2002) The role of microstructure of nickel-aluminium-bronze alloy on its cavitation corrosion behavior in natural seawater. Mater Charact 48(1):37-41

27. Duplex stainless steel IMOA (2013). http://www.imoa.info/moly_ uses/moly_grade_stainless_steels/duplex_stainless_steel.php. Accessed 28 Aug 2013

28. Culpan EA, Rose G (1978) Microstructural characterization of cast nickel aluminium bronze. J Mater Sci 13(8):1647-1657

29. Hasan F, Iqbal J, Ridley N (1985) Microstructure of as-cast aluminium bronze containing iron. Mater Sci Technol 1(4):312-315

30. Faires KB (2003) Characterization of microstructure and microtexture in longitudinal sections from friction stir processed nickel-aluminum bronze. North Carolina State University

31. Takaloo AV, Daroonparvar MR, Atabaki MM, Mokhtar K (2011) Corrosion behavior of heat treated nickel-aluminum bronze alloy in artificial seawater. Mater Sci Appl 02(11):1542-1555

32. Lorimer GW, Hasan F, Iqbal J, Ridley N (1986) Observation of microstructure and corrosion behaviour of some aluminium bronzes. Br Corros J 21(4):244-248

33. Culpan EA, Rose G (1979) Corrosion behaviour of cast nickel aluminium bronze in sea water. Br Corros J 14(3):160-166

34. Al-Hashem A, Riad W (2002) The effect of duplex stainless steel microstructure on its cavitation morphology in seawater. Mater Charact 47(2001):389-395

35. Fredriksson W (2012) Depth Profilling of the Passive Layer on Stainless Steel using Photoelectron Spectroscopy. Uppsala Universitet

36. Daroonparvar A, Atabaki MR, Mazar, Vakilipour M (2011) Effect of pre-heat treatment on corrosion behaviour of nickel-aluminium bronze alloy. Assoc Metall Eng Serbia 17(4):183-198

37. Neville A, Hodgkiess T, Dallas JT (1995) A study of the erosioncorrosion behaviour of engineering steels for marine pumping applications. Wear 186:497-507

38. Wood RJK, Hutton SP (1990) The synergistic effect of erosion and corrosion: published results

39. Kwok C, Cheng F, Man H (2000) Synergistic effect of cavitation erosion and corrosion of various engineering alloys in $3.5 \% \mathrm{NaCl}$ solution. Mater Sci Eng A 290(1):145-154 